\title{
Impact of Year-Round and Traditional School Schedules on Summer Weight Gain and Fitness Loss
}

\author{
Timothy A. Brusseau, PhD,' Ryan D. Burns, PhD,' You Fu, PhD,' and R. Glenn Weaver, PhD³
}

\section{Abstract}

Background: Summer weight gain and fitness loss has been identified as a public health concern for children. The objective of this study was to compare changes in weight status and cardiovascular fitness in children attending year-round and traditional calendar schools.

Methods: Participants were 321 children from a traditional and year-round school. BMI and Progressive Aerobic Cardiovascular Endurance Run (PACER) Laps were collected during school. Multilevel general linear mixed-effects models were utilized to examine changes in BMI and PACER over the summer while also considering summer camp and sport participation.

Results: Children had higher BMI $z$-scores during Fall 2018 compared with Spring $2018(b=0.09, p=0.006)$. This effect was modified by Break Length, as students with 3 -week $(b=-0.09, p=0.012)$ and 7-week breaks $(b=-0.10, p=0.003)$ displayed attenuated increases in BMI $z$-scores compared with 12-week breaks. For PACER Laps, students who participated in summer sports displayed improvements compared with nonparticipants $(b=4.6$ laps, $p=0.001)$.

Conclusions: Shorter summer breaks appear to have a protective effect on summer weight gain when compared with a traditional 12 -week break. In addition, children who participated in organized sport over the summer did see a significant improvement in cardiovascular fitness. Schools might consider a year-round school calendar for its potential to protect against summer weight gain.

Keywords: BMI; cardiovascular fitness; children; sport participation; summer break; weight gain

\section{Introduction}

$\mathbf{O}$ verweight and obesity, ${ }^{1}$ as well as poor levels of fitness ${ }^{2}$ continue to be a public health concern for children and adolescents. Historically, schools have been identified as a potential solution to these concerns, primarily due to the fact that most children attend school, where they have the facilities, infrastructure, and equipment that will allow most children to be physically active. ${ }^{3}$ In their review of school year and summer weight gain patterns, Baranowski et al. ${ }^{4}$ found that the most common period associated with weight gain was the summer months. They also found that the most common outcome during the summer was accelerated weight gain (or increases in BMI) in overweight and obese youth whereas healthy weight youth gained less weight or, in some instances, were able to maintain their weight status. Similarly, in their review, Franckle et al..$^{5}$ found that there was a trend for increased weight gain during summer vacation, especially in ethnic minority and overweight children.

Studies have also highlighted both weight gain and fitness loss in children over the summer compared with the school year. ${ }^{6}$ Recently, two studies have highlighted a concern that the improvements in weight status and aerobic fitness garnered during a school physical activity intervention were lost during the 12 -week summer break. ${ }^{7,8}$ Weaver et al. ${ }^{9}$ have suggested that one of the reasons that we have struggled to address childhood obesity is that we have primarily focused on school programming and neglected the 3-month summer break during which children are not in school. In fact, Brazendale et al. ${ }^{10}$ suggest that these changes in weight status and fitness over the summer could be attributed to the structured day hypothesis. The structured days hypothesis posits that a structured day, defined as a preplanned, segmented, and adult-supervised compulsory environment, protects children against obesogenic behaviors.

\footnotetext{
'Department of Health, Kinesiology, and Recreation, University of Utah, Salt Lake City, UT.

${ }^{2} \mathrm{~S} c h o o l$ of Community Health Sciences, University of Nevada, Reno, Reno, NV.

${ }^{3}$ Department of Exercise Science, Arnold School of Public Health, University of South Carolina, Columbia, SC.
} 
This protection, ultimately, prevents the occurrence of negative health outcomes, in this case, excessive weight gain and loss in fitness. The structured days hypothesis is founded in the "filled-time perspective" literature, which posits that time filled with favorable activities cannot be filled with unfavorable activities. ${ }^{11}$ This perspective would lead to the hypothesis that children engage in a greater number of obesogenic behaviors that lead to increased weight gain on less-structured days (e.g., weekend and summer days) than on structured days (e.g., school days). They specifically highlight that when children have regular structured days (e.g., school) they have more favorable activities and/or routines for physical activity, diet, sleep, and screen time. For example, the school day provides scheduled activity times, including active commuting, recess, physical education, and afterschool programming. Similarly, schools provide access to regulated food programs for breakfast and lunch. Lastly, school days regulate how much screen time children may have access to and encourage a consistent bed time routine. ${ }^{11}$

It has been suggested that one possible solution to summer weight gain and fitness loss may be structured summer programming, most notably summer camps. ${ }^{9}$ Studies have demonstrated the potential of summer camps for improving and/or maintaining health weight over the summer. ${ }^{12,13}$ Weaver et al. ${ }^{9}$ also suggests that a major limitation to summer camps is the fact that they are fee for service, which may limit the accessibility of this type of programming for many children from low-income households. Brusseau and Burns ${ }^{7}$ went on to theorize that yearround schooling might be a potential solution to protecting students from weight gain and fitness loss in the summer by eliminating the traditional 12-week summer break and replacing it with shorter breaks spread out across the academic calendar. Of note, Weaver et al. ${ }^{14}$ found that children's sleep patterns shift as early as the first week of a school break whereas children are $33 \%$ more sedentary by week 3 of a school break.

Increasingly, more children are attending year-round schools; in fact, recent data suggest that 46 states have more than 3000 year-round schools that are attended by $\sim 10 \%$ of the children in the United States. ${ }^{15}$ In addition, year-round schooling has been identified as a solution for two educational issues in the United States. First, it has been theorized that year-round schooling could improve academic achievement by eliminating the traditional long summer breaks where students often lose some of the knowledge they have gained during the academic year. ${ }^{16}$ Second, year-round schooling has become increasing popular as a way to deal with school growth and overcrowding. To minimize class size and utilize the school space in the best way possible, schools have increasingly added year-round track systems where children have different breaks to improve the educational environment. ${ }^{17}$ Research has contradicted the academic benefits of yearround schooling ${ }^{18,19}$; specifically, studies have shown no difference in academic achievement across all students and when looking at specific ethnic minority student groups.
Despite the lack of research supporting its academic benefits, the growth of year-round schooling has been significant. ${ }^{20}$ To date, little is known about the role that a yearround school calendar might play in summer weight gain and fitness loss. Therefore, the purpose of this study was to examine the changes in BMI and cardiovascular fitness during year-round and traditional school summer breaks. A secondary purpose was to examine the modifying role that self-reported summer camp and organized physical activity participation might have on these outcomes.

\section{Methods}

\section{Participants and Setting}

Participants were a convenience sample of $328(160=$ males, $168=$ females) children in grades $1-5$ from two elementary schools in the same school district in the Southwestern United States. Schools were exactly four miles apart with similar demographic characteristics, academic achievement, school layouts, physical activity space, and physical activity opportunities. These schools were neighborhood schools with set boundaries that dictated enrollment. Table 1 shows the characteristics of the schools. The traditional calendar school had a 12-week summer break. The year-round calendar school had either a 3- or 7-week summer break, depending on the assigned track. The necessity of the year-round calendar was due to overcrowding and not for a solely academic reason. Children would have 45 days in class followed by a 15 school day break. At any given time, one track was out of school to ensure that space was available for classes. All children had a 3-week July break, and some children had a 7-week break if they were off track (out of school) during the 4 weeks at the end of the school year or the 4 weeks at the beginning.

\begin{tabular}{l|c|c}
\hline Table I. School Characteristics \\
\hline Student enrollment & $\begin{array}{c}\text { Traditional } \\
\text { school } \\
1033\end{array}$ & $\begin{array}{c}\text { Year-round } \\
\text { school }\end{array}$ \\
\hline Ethnic minority & $16 \%$ & 1153 \\
\hline Low income & $8 \%$ & $11 \%$ \\
\hline Certified teachers & 40 & $12 \%$ \\
\hline $\begin{array}{l}\text { Standardized } \\
\text { testing average }\end{array}$ & $56 \%$ & 48 \\
\hline Grades & K-6 & $51 \%$ \\
\hline Calendar & $\begin{array}{c}\text { Traditional } \\
\text { August-May }\end{array}$ & $\begin{array}{c}\text { Year round (4 tracks) } \\
45 \text { days on I5 days off }\end{array}$ \\
\hline Physical education & I day/week & I day/week \\
\hline
\end{tabular}

Certified teachers, teachers with licensure as approved by the State of Utah; ethnic minority, groups with different national or cultural traditions from the main population; low income, percent receiving free/reduced lunch. 
Participant recruitment took place by sending parental permission letters home to all first to fifth grade families early in the spring semester. Parental written permission was ascertained by the parent's returning the signed permission forms. Any student who had a returned parental permission form was invited to participate and the student was explained the study during physical education class and provided written assent before the start of the study. Although it is difficult to determine whether there were differences in the parents/children who chose to participate and those who did not, it appears that the sample was representative of the broader school population. The University of Utah Institutional Review Board, school district research board, and school principals approved all procedures and methodology.

\section{Measures}

Height was measured without shoes to the nearest $0.01 \mathrm{~m}$ by using a portable stadiometer (Seca 213; SECA, Hanover, $\mathrm{MD}$ ), and weight was measured to the nearest 0.1 kilogram by using a digital scale (BD-590, Tanita, Tokyo, Japan) during physical education classes. BMI was calculated by taking a student's weight in kilograms divided by the square or his or her height in meters $\left(\mathrm{kg} / \mathrm{m}^{2}\right)$. BMI $z$-scores were calculated by using STATA's "zanthro" package using age (in years) and the 2000 U.S. CDC Growth Chart. Cardiovascular fitness was measured by using the 20 -m Progressive Aerobic Cardiovascular Endurance Run (PACER), ${ }^{21}$ administered during physical education classes. The PACER was conducted in the schools' gymnasium with background music provided by a CD. Each student was instructed to run from one floor marker to another floor marker across a 20-m distance within an allotted time frame. The time to complete the run between the floor markers steadily decreased as the test progressed. Once a student could not complete the distance in the allotted time on two occasions, their score was recorded in laps. The PACER is a valid and reliable test for measuring cardiovascular fitness in children. ${ }^{21}$ All tests were led by three members of the research team who had been trained in and had experience with each of the testing procedures.

Students were also asked four questions in August regarding their summer break physical activity participation: (1) Did you participate in summer camp? (2) If so, for how many weeks? (3) Did you participate in organized sport or physical activity over the summer? (4) If so, on average how many days per week? Questions were read aloud by the research team; verbal examples of camp and physical activity opportunities were explained to the students, and students could ask about any specific example that they might have had. Students also self-reported their age and sex on the administered questionnaire.

\section{Procedures}

All data were collected in back-to-back weeks (the yearround school followed by the traditional school to keep the measures as close together as possible). Each class was split into two groups of students to ensure that they had enough space to safely complete the PACER in the gymnasium. One group of students completed the PACER, whereas the other students had their height and weight measured in a semi-private area of the gym. These procedures were repeated at each school first in May and then 12 weeks later in August. During the August data collection, students were given the four questions to answer regarding their summer organized physical activity and camp participation.

\section{Data Processing}

There were two outcome variables in this study: BMI $z$ scores and PACER Laps, both on the continuous measurement scale. Seven cases ( 6 girls, 1 boy) were dropped for missing data to yield an analyzed sample of 321 children. Differences among break lengths during Spring 2018 were examined by using one-way ANOVA tests with a Bonferroni $\alpha$ level adjustment for the continuous variables and Pearson's chi-square tests for the count variables. All predictor variables were treated on the categorical measurement scale. Time was treated as a dichotomous variable with Spring 2018 as the referent. Summer Break Length was treated as a three-level categorical variable with the Traditional School programming as the referent (i.e., 12-weeks). Both Summer Sports and Summer Camps were treated as dichotomous predictors with not playing summer sports and not attending summer day camps as the referents, respectively.

\section{Statistical Analysis}

Data were screened for outliers by using $z$-scores (using a $\pm 3.0 \mathrm{z}$ cut-point) and checked for Gaussian distributions by using $k$-density plots. To observe the trends in BMI $z$ scores and PACER laps before and after summer break and the modifying effect of Break Length, and Summer Sport and Summer Camp participation, multilevel general linear mixed-effects models were employed by utilizing maximum likelihood estimation. Two separate models were run, one for each outcome variable. Random intercepts were employed on the classroom and student levels to adjust for clustering within the data structure (i.e., students clustered within classrooms, time-point measurements clustered within students). School was not included as a higher level because of the small number of clusters $(N=2)$. Likelihood ratio tests were employed to examine the utility of multilevel modeling against the null model that assumed no clustering within the data structure. Time was the primary predictor of interest with Break Length, Summer Sports, and Summer Camps tested as effect modifiers within each of the models via derivation of two-way and three-way interaction terms. Models were adjusted for age and sex. Only the PACER model was adjusted for age and sex because age and sex were used to calculate BMI $z$-scores. Reporting of the results included the adjusted parameter estimates with corresponding $95 \%$ Confidence Intervals. $\alpha$ Level was set at $p<0.05$, and all analyses were carried out by using STATA v.15.0 statistical software package (STATA, College Station, TX). 


\section{Results}

Descriptive statistics are presented in Table 2. Eighty children had a 3 -week summer break ( $24.4 \%$ of sample), 66 children had a 7 -week summer break (20.1\% of sample), and 175 children had a 12 -week summer break $(53.4 \%$ of sample). In addition, the frequency of participating in summer sports ranged from 0 to 7 days per week, with a sample average of 2.4 days per week $(\mathrm{SD}=2.1)$ and frequency of participating in summer camps ranged from 0 to 5 weeks with a sample average of 0.50 weeks $(\mathrm{SD}=1.01)$. There were no statistical differences during Spring 2018 among summer break lengths on BMI $z$-scores $(p=0.100)$, PACER laps $(p=0.171)$, age $(p=0.580)$, sex distribution $(p=0.749)$, participation in summer sports $(p=0.756)$, and participation in summer camps $(p=0.087)$. Results from the general linear mixed-effects models are reported in Tables 3 and 4 for BMI $z$-scores and PACER laps, respectively. For $\mathrm{BMI} z$-scores, there was a statistically significant time main effect, suggesting marginally higher BMI during Fall 2018 compared with Spring $2018(p=0.006)$. However, this time effect was modified by Break Length, with students with 3and 7-week breaks displaying attenuated increases in BMI compared with students enrolled in Traditional Schooling with 12 -week breaks $(p<0.05)$. Figure 1 displays the BMI $z$-scores across summer break lengths. No statistically significant three-way interactions were present among any of the observed variables on BMI.

For PACER laps, there was no time main effect; however, students who participated in summer sports displayed increases in PACER laps compared with students who did not participate in summer sports $(p=0.001)$. There was no Break Length $\times$ Time interaction for PACER laps. No three-way interactions were found on PACER Laps.

\begin{tabular}{|c|c|c|c|}
\hline & $\begin{array}{l}\text { 3-Week } \\
\text { break }\end{array}$ & $\begin{array}{l}\text { 7-Week } \\
\text { break }\end{array}$ & $\begin{array}{l}\text { I2-Week } \\
\text { break }\end{array}$ \\
\hline Age (years) & $9.8(1.2)$ & $9.0(1.3)$ & $9.0(1.5)$ \\
\hline BMI z-score & $0.19(1.02)$ & $-0.17(0.83)$ & $-0.10(0.92)$ \\
\hline PACER laps & $20.7(8.5)$ & $26.2(14.8)$ & $24.7(13.7)$ \\
\hline Girls & 39 (12.1\%) & $33(10.3 \%)$ & $90(28.0 \%)$ \\
\hline $\begin{array}{l}\text { Played summer } \\
\text { sports }\end{array}$ & 56 (17.3\%) & 47 (14.4\%) & $103(31.5 \%)$ \\
\hline $\begin{array}{l}\text { Attended summer } \\
\text { camps }\end{array}$ & $28(8.6 \%)$ & 12 (3.7\%) & $39(12.0 \%)$ \\
\hline
\end{tabular}

PACER, Progressive Aerobic Cardiovascular Endurance Run.

\begin{tabular}{|c|c|c|c|}
\hline & b-Coefficient & 95\% Cl & $p$ \\
\hline Time & $0.09^{a}$ & $0.03-0.15$ & 0.004 \\
\hline 3-Week break & 0.38 & -0.39 to 1.24 & 0.389 \\
\hline 7-Week break & 0.03 & -0.31 to 0.35 & 0.901 \\
\hline 3-Week break $\times$ time & $-0.10^{\mathrm{a}}$ & -0.17 to -0.04 & 0.009 \\
\hline 7-Week break $\times$ time & $-0.1 I^{a}$ & -0.18 to -0.04 & 0.001 \\
\hline Played summer sports & 0.08 & -0.14 to 0.31 & 0.495 \\
\hline Sports $\times$ time & -0.01 & -0.09 to 0.08 & 0.821 \\
\hline Attended summer camp & 0.06 & -0.23 to 0.33 & 0.764 \\
\hline Camp $\times$ time & 0.05 & -0.03 to 0.12 & 0.465 \\
\hline
\end{tabular}

Referent for time is Spring 2018; referent for summer break length is 12 weeks (traditional school); referent for summer sports is not playing; referent for summer camps is not attending.

Bold and a denote statistical significance, $p<0.05$.

$\mathrm{Cl}$, confidence interval.

\section{Discussion}

The purpose of this study was to examine the impact of year-round and traditional school calendars on summer weight gain and fitness loss. A secondary purpose was to determine whether self-reported summer camp

\section{Table 4. Parameter Estimates} for the PACER Lap General Linear Mixed-Effects Model

\begin{tabular}{l|c|c|c} 
& b-Coefficient & $\mathbf{9 5 \%} \mathbf{C l}$ & $\boldsymbol{P}$ \\
\hline Time & 2.2 & -0.4 to 4.9 & 0.099 \\
\hline 3-Week break & -5.3 & -17.6 to 7.1 & 0.406 \\
\hline 7-Week break & 3.1 & -2.6 to 8.8 & 0.290 \\
\hline 3-Week break $\times$ time & -2.1 & -10.5 to 6.2 & 0.619 \\
\hline 7-Week break $\times$ time & -1.3 & -4.3 to 1.7 & 0.388 \\
\hline Played summer sports & 1.5 & -2.1 to 5.1 & 0.429 \\
\hline Sports $\times$ time & $\mathbf{4 . 6}$ & $2.0-7.2$ & 0.001 \\
\hline $\begin{array}{l}\text { Attended summer } \\
\text { camp }\end{array}$ & 3.0 & -0.7 to 6.6 & 0.115 \\
\hline Camp $\times$ time & & & \\
\hline Age $($ years) & 0.09 & -2.5 to 2.7 & 0.943 \\
\hline Female & $\mathbf{4 . 0 6 ^ { \mathrm { a } }}$ & $3.42-5.80$ & $<0.001$ \\
\hline
\end{tabular}

Referent for time is Spring 2018; referent for summer break length is 12 weeks (traditional school); referent for summer sports is not playing; referent for summer camps is not attending.

Bold and a denote statistical significance, $p<0.05$. 


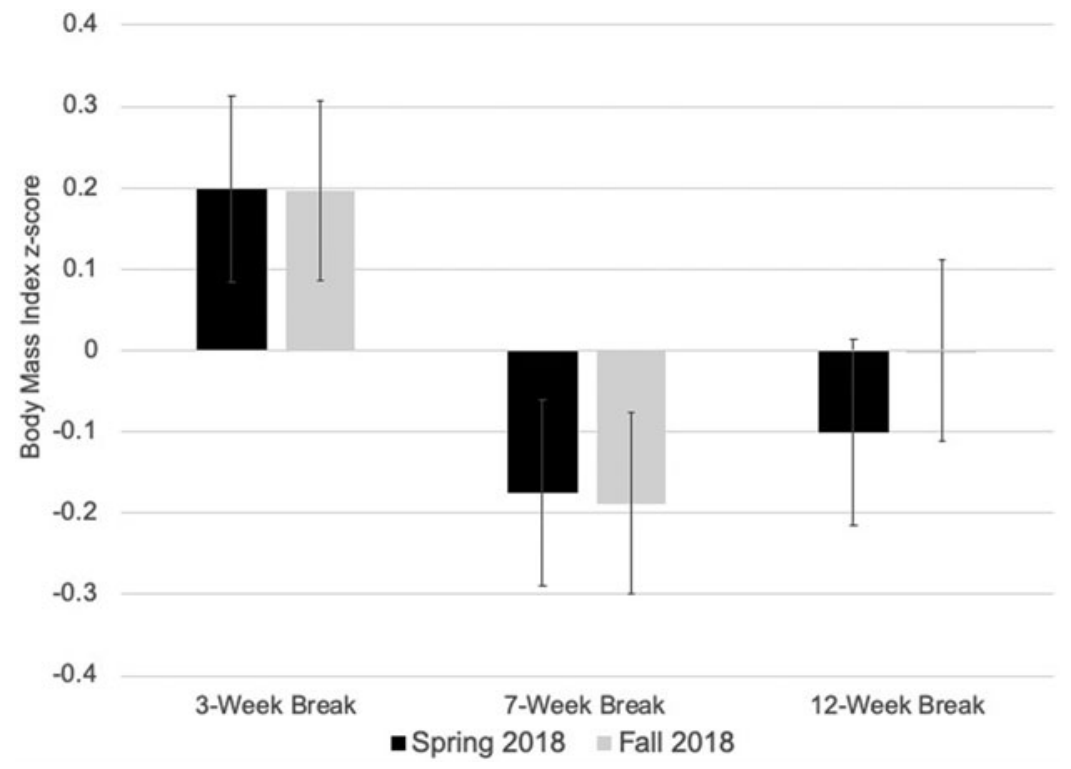

Figure 1. BMI z-scores across summer break lengths.

and organized physical activity participation impacted these changes.

This study is the first to explore the impact of a yearround track system school calendar (e.g., 3- and 7-week breaks) on health-related fitness outcomes. Current findings suggest that the shorter breaks associated with the year-round calendar mitigated summer weight gain. With scholars continuing to highlight the summer months as a period where obesity prevalence grows in children, ${ }^{22}$ yearround schooling may be a solution to this public health pandemic. The benefits of the year-round calendar appear to be explained by the structured day hypothesis. ${ }^{10}$ The school day ensures structure for children, which can lead to healthy lives of physical activity, sleep, and diet. More specifically, schools provide opportunities for physical activity. Schools in this study provided at least two recess opportunities each day as well as physical education once per week. These segments alone can provide substantial physical activity. ${ }^{23,24}$ In addition, studies have shown the significant decreases in daily physical activity on nonschool days (e.g., weekends), which highlight the importance of the school structure. ${ }^{25}$ Alexander and Lyons ${ }^{26}$ reported that children in year-round schooling showed significant accelerated gains in BMI during winter compared with previous summers. This study showed mitigated increases in BMI $z$-scores during summer, but it is unknown how BMI would fluctuate across the winter months. Nevertheless, this study is the first to compare varying summer break lengths on BMI $z$-score change, which provides additional information on the potential health benefits of year-round schooling. Comparing BMI variability among summer break length groups across the entire year should be a priority for research. Although relatively small in magnitude across one summer, the attenuated increases in BMI $z$-scores in those children who were in a 3- and 7-week summer break may be clinically relevant if sustained across multiple years. However, it is unknown whether these effects are consistent within individual students. The school calendar did not appear to impact cardiovascular fitness in the participating children.

The current findings did, however, indicate that organized sport participation during summer break was a key factor in increasing cardiovascular fitness. An improvement of $\sim 4$ laps was observed in those children who participated in summer sports. Similar to the effects observed with BMI $z$-scores, these improvements in aerobic fitness may be clinically relevant if sustained across multiple summers. In addition, because even modest improvement in aerobic fitness is associated with better cardiometabolic risk, small improvements in PACER laps may yield meaningful reductions in potential health risk. Recent research has suggested that sport participation is associated with improved body composition and cardiovascular fitness when compared with nonsport participants. ${ }^{27}$ Marques et al. ${ }^{28}$ clearly link those with greater sport participation to greater levels of moderate to vigorous physical activity. Phillips and Young ${ }^{29}$ have also linked sport participation to both increases in energy expenditure and physical fitness for inner city females. Although organized sport is a great opportunity for physical activity out of school, it is important to recognize that the cost of youth sport may be prohibitive for many families. The current sample included about $8 \%-12 \%$ of children who would be considered as coming from a lowincome background based on free and reduced lunch participation. Future work in schools that serve predominantly low-income families is needed to further elucidate the role of organized sport in summer fitness.

Summer camp participation did not play a role in either weight gain or cardiovascular fitness levels in this study. Traditionally, summer camps have been shown to help 
students exceed national physical activity recommendations. ${ }^{30}$ Also, a growing number of summer camps participate in the USDA Summer Food Service Program, which sets nutritional guidelines related to quantity and quality of food served in programs that serve children from low-income households. ${ }^{31}$ Summer camps may also regulate children's sleep similar to the way that a school does during the school year. These benefits protect students from weight gain and fitness loss. The contradictory findings in this study may be a result of the relatively low percentage of students who participated in summer camps and the fact that most children who did participate only attended 1 week of camp. Previous research has reported that school-sponsored summer programming has the ability to protect students from weight gain and fitness loss when compared with youth not participating in these programs. ${ }^{32}$ This particular study included more traditional school-based academic school programs that were not available for these students at their schools in this study.

Although this study is the first to examine the impact of year-round school calendars on summer weight gain and fitness loss, it is not without limitations. The inclusion of only two schools that were not randomized and from only one suburban school district limits its generalizability. Similarly, the study lacked overall demographic diversity and we were unable to collect ethnicity and socioeconomic data at the individual level. The use of self-reported sport and camp participation at the end of the summer may also be a concern due to recall related issues. Lastly, summer physical activity levels, sleep, and dietary habits were not measured. Future work is needed to replicate this study across numerous schools, districts, cities, and states while also considering measures of physical activity, sleep, and diet.

In conclusion, this study serves as a first look at the potential health benefits of the year-round school calendar, specifically the potential to protect against an increase in weight status over the summer months. In addition, summer-organized sport participation appears to be an important avenue for maintaining even improving aerobic fitness when children are out of school. Clearly, more work is needed to replicate and generalize these findings. Although the academic benefits of year-round schools appear to be limited, this study provides data that may be used by school districts that may want to consider year-round school calendars for health benefits rather than academic or overcrowding concerns.

\section{Author Disclosure Statement}

No competing financial interests exist.

\section{References}

1. Abarca-Gómez L, Abdeen ZA, Hamid Z, et al. Worldwide trends in body-mass index, underweight, overweight, and obesity from 1975 to 2016: A pooled analysis of 2416 population-based mea- surement studies in $128 \cdot 9$ million children, adolescents, and adults. Lancet 2017;390:2627-2642.

2. Bai Y, Saint-Maurice PF, Welk GJ, et al. Prevalence of youth fitness in the United States: Baseline results from the NFL PLAY 60 FITNESSGRAM partnership project. J Pediatr 2015;167:662-668.

3. Khambalia AZ, Dickinson S, Hardy LL, et al. A synthesis of existing systematic reviews and meta-analyses of school-based behavioural interventions for controlling and preventing obesity. Obes Rev 2012;13:214-233.

4. Baranowski T, O'Connor T, Johnston C, et al. School year versus summer differences in child weight gain: A narrative review. Child Obes 2014;10:18-24.

5. Franckle R, Adler R, Davison K. Accelerated weight gain among children during summer versus school year and related racial/ ethnic disparities: A systematic review. Prev Chronic Dis 2014;11: E101.

6. von Hippel PT, Powell B, Downey DB, et al. The effect of school on overweight in childhood: Gain in body mass index during the school year and during summer vacation. Am J Public Health 2007;97:696-702.

7. Brusseau TA, Burns RD. Children's weight gain and cardiovascular fitness loss over the summer. Int J Environ Res Public Health 2018; 15:2770.

8. Fu Y, Brusseau TA, Hannon JC, et al. Effect of a 12-week summer break on school day physical activity and health-related fitness in low-income children from CSPAP schools. J Environ Public Health 2017;2017:9760817.

9. Weaver RG, Beets MW, Brazendale K, et al. Summer weight gain and fitness loss: Causes and potential solutions. Am J Lifestyle Med 2018;13:116-128.

10. Brazendale K, Beets MW, Weaver RG, et al. Understanding differences between summer vs. school obesogenic behaviors of children: The structured days hypothesis. Int J Beh Nutr Phys Act 2017;14:100.

11. Caldwell LL, Smith EA. Leisure as a context for youth development and delinquency prevention. Aust N Z J Criminol 2006;39:398-418.

12. Hopkins LC, Holloman C, Melnyk B, et al. Participation in structured programming may prevent unhealthy weight gain during the summer in school-aged children from low-income neighbourhoods: Feasibility, fidelity and preliminary efficacy findings from the Camp NERF study. Public Health Nutr 2019;1-13.

13. Moreno JP, Johnston CA, Woehler D. Changes in weight over the school year and summer vacation: Results of a 5-year longitudinal study. J Sch Health 2013;83:473-477.

14. Weaver RG, Beets MW, Perry M, et al. Changes in children's sleep and physical activity during a 1-week versus a 3-week break from school: A natural experiment. Sleep 2019;42:zsy205.

15. Statistic Brain Research Institute. Year round school statistics. Available at www.statisticbrain.com/year-round-school-statistics (Last accessed June 15, 2019).

16. Cooper H, Nye B, Charlton K, et al. The effects of summer vacation on achievement test scores: A narrative and meta-analytic review. Rev Educ Res 1996;66:227-268.

17. Graves J. The academic impact of multi-track year-round school calendars: A response to school overcrowding. J Urban Econ 2010;67:378-391.

18. McMullen SC, Rouse KE. The impact of year-round schooling on academic achievement: Evidence from mandatory school calendar conversions. Am Econ J Econ Policy 2012;4:230-252.

19. Wu AD, Stone JE. Does year round schooling affect the outcome and growth of California's API Scores?. J Educ Res Policy Studies 2010;10:79-97. 
20. Cooper H, Valentine JC, Charlton K, et al. The effects of modified school calendars on student achievement and on school and community attitudes. Rev Educ Res 2003;73:1-52.

21. Welk G, Meredith MD. Fitnessgram and Activitygram Test Administration Manual-Updated, 4th ed. Human Kinetics, Champaign, IL, 2010.

22. von Hippel PT, Workman J. From kindergarten through second grade, US children's obesity prevalence grows only during summer vacations. Obesity (Silver Spring) 2016;24:2296-2300.

23. Brusseau TA, Kulinna PH, Tudor-Locke C, et al. Pedometerdetermined segmented physical activity patterns of fourth-and fifth-grade children. J Phys Act Health 2011;8:279-286.

24. Weaver RG, Crimarco A, Brusseau TA, et al. Accelerometry-derived physical activity of first through third grade children during the segmented school day. J Sch Health 2016;86:726-733.

25. Brusseau TA. The intricacies of children's physical activity. J Hum Kinet 2015;47:269-275.

26. Alexander AG, Lyons PE. Rebound body mass index growth in year-round elementary education students of largely Hispanic descent undergoing obesity interventions. J School Health 2016;86: 181-186.

27. Agata K, Monyeki M. Association between sport Participation, body composition, physical fitness, and social correlates among adolescents: The PAHL study. Int $J$ Environ Res Public Health 2018;15:2793.

28. Marques A, Ekelund U, Sardinha LB. Associations between organized sports participation and objectively measured physical activity, sedentary time and weight status in youth. J Sci Med Sport 2016;19:154-157.

29. Phillips JA, Young DR. Past-year sports participation, current physical activity, and fitness in urban adolescent girls. $J$ Phys Act Health 2009;6:105-111.

30. Brazendale K, Beets MW, Weaver RG, et al. Children's moderate to vigorous physical activity attending summer day camps. Am J Prev Med 2017;53:78-84.

31. United States Department of Agriculture. Summer Food Service Program (SFSP): Serving Summer Meals. 2017. Available at www.fns.usda.gov/sfsp/serving-summer-meals

32. Park KS, Lee MG. Effects of summer school participation and psychosocial outcomes on changes in body composition and physical fitness during summer break. J Exerc Nutr Biochem 2015; 19:81-90.

Address correspondence to: Timothy A. Brusseau, PhD

Department of Health, Kinesiology, and Recreation University of Utah $250 S 1850 \mathrm{E}$ Salt Lake City, UT 84112 E-mail: tim.brusseau@utah.edu 